RECIIS - R. Eletr. de Com. Inf. Inov. Saúde. Rio de Janeiro, v5, n.4, p.97-108, Dez., 2011

[www.reciis.icict.fiocruz.br] e-ISSN 1981-6278

* Artigo Original

\title{
'Aqui sofro demais': notas de uma pesquisa em um Hospital de Custódia e Tratamento
}

\section{Márcia Cristina Maciel de Aguiar}

Departamento de Neurociências, Faculdade de Medicina, Universidade Federal da Bahia, Bahia, Brasil mmdeaguiar@yahoo.com.br

\author{
Luiz Claudio Lourenço \\ Faculdade de Filosofia e Ciências Humanas, Universidade Federal da Bahia, Bahia, Brasil \\ luiz.lourenco@uol.com.br
}

DOI: $10.3395 /$ reciis.v5i4.561pt

\begin{abstract}
Resumo
Este trabalho traz aspectos particulares metodológicos detectados durante o trabalho de campo de uma pesquisa em ciências sociais em andamento, que visa a compreender a doença, o crime e a internação num dos hospitais de custódia e tratamento deste país. Trata-se de uma pesquisa qualitativa que adota uma perspectiva próxima do interacionismo simbólico, com recursos metodológicos da teoria fundamentada. Inicialmente expõe-se um pouco das ambivalências institucionais que nos despertaram interesse e são descritas características gerais do objeto de estudo, deixando-se claro que são entendidos como internos todos aqueles que vivenciam o cotidiano da instituição, categorizados como internos-pacientes e internos-funcionários. Em seguida, são apresentados os procedimentos técnicos adotados tanto na obtenção quanto na análise dos dados e, posteriormente, são discutidos os aspectos decorrentes do background e da familiaridade do pesquisador com o sujeito da pesquisa; o acúmulo de papéis e as dificuldades de diferenciá-los na prática de campo; a relação do pesquisador nativo (ou quase nativo) com seu universo de pesquisa e as facilidades e dificuldades decorrentes disso. Estas discussões são feitas na medida em que são descritas algumas das interações com os diversos atores sociais que compõem o campo. Espera-se com este trabalho, contribuir minimamente na construção metodológica de outros similares, trazendo também a possibilidade de fomentar alguma reflexão sobre o campo estudado.
\end{abstract}

Palavras-chave: Psicose; Crime; Internação

\section{I ntrodução}

Discutir aspectos metodológicos e o andamento de uma pesquisa num Hospital de Custódia e Tratamento - HCT passa necessariamente por debater também as suas principais questões substantivas, muitas vezes incontornáveis, no cotidiano do trabalho de campo. Por se tratar de um trabalho fruto de uma pesquisa sem precedentes ${ }^{1}$ e por limitação de espaço, este texto se aterá à exposição de alguns achados e aspectos metodológicos adotados para um multi e interdisciplinar estudo de características, feito a partir de técnicas das ciências sociais. Entende-se que os HCT's do nosso país são um campo riquíssimo, à espera de estudos que desvendem os seus mistérios, significados, sentidos e motivos. Sua cultura e características sui generis formam um mundo quase autônomo, que estabelece fronteiras que vão além das barreiras físicas entre a sociedade dos "normais" e a sociedade dos "loucos e perigosos".

Sabe-se que sempre houve uma distância entre o ideal para o qual a instituição HCT foi pensada e como ela de fato opera em nosso país. O que nos chama atenção é a ambigüidade decorrente de uma instituição que, na prática, faz punir e não consegue tratar adequadamente o adoecimento psíquico de seus internos; um lugar que no dia-a-dia armazena dentro de si seres humanos indesejáveis ao convívio social, sem ter clareza de se eles devem ser punidos ou tratados. Esta foi a mola propulsora desta empreitada de pesquisa. Afinal, como podemos vislumbrar, através das vivências dos internos, aspectos de uma instituição que deveria cuidar, mas que, efetivamente, funciona como meio de punição?

É necessário destacar que uma pesquisa em HCT acaba necessariamente mobilizando aspectos de diferentes campos de conhecimento. Neste desafio, vimo-nos diante de várias possibilidades para construir questões com referências na sociologia do crime, nos estudos prisionais, além do campo da saúde mental e da psiquiatria forense. Em nossa experiência clínica com pacientes psicóticos, 
acreditamos que seja importante a construção de sentido que os sujeitos fazem de suas vivências, e como lidam com isto no seu cotidiano. Optamos por estudar a psicose, o crime e a internação, a partir das vivências narradas pelos pacientes em estudo, psicóticos e homicidas, e das observações diretas feitas no campo. Queremos compreender como pensam e representam a sua doença, o crime, e a internação no HCT. Como estes sujeitos ali internados compreendem seu lugar dentro desta instituição? Como constroem suas redes de sociabilidade junto aos demais internos e o corpo de funcionários que ali trabalha? Como entendem seus delitos e as formas de punição dos mesmos?

A fala que dá título a este texto, "Aqui sofro demais", é comum tanto para pacientes quanto para funcionários. A prática do campo também logo apontou muito mais a proximidade que a distância entre as mazelas vivenciadas por ambos. Foi fácil notar que todos que estão ali internados (pacientes ou funcionários) compõem o mesmo universo simbólico de sociabilidade e de interação. Os funcionários definem e lidam com o crime, passam no HCT parte significativa de suas vidas, absorvem a cultura e as mazelas da instituição. Por isso, foram adotadas as designações de internospacientes - IPs e internos-funcionários - IFs, considerando a ambos como internos, e incluídas como uma preocupação analítica as vivências destes últimos, assim como o impacto neles ocorrido, a partir do seu trabalho e da rotina institucional.

\section{Hospital de Custódia e Tratamento}

O Manicômio Criminal surgiu, de acordo com Carrara (1998), em vários países ao mesmo tempo, na passagem do século XIX para o século XX, a partir do momento em que nos tribunais se observou que nem os asilos, nem as prisões mostravam-se adequados à segregação de alguns criminosos classificados como degenerados. O decreto 1.132 de 1903, no Brasil, organizou a assistência médicolegal aos alienados, e propôs a construção, para os alienados criminosos, de manicômios criminais também conhecidos como manicômios judiciários - e, enquanto estes não existissem, a construção de anexos nos asilos públicos para abrigá-los.

No século XX, vamos encontrar os semi-hospícios ou semiprisões, para receber os doentes mentais criminosos. Apesar da lei de 1903, os "manicômios criminais" só surgiram quase 20 anos depois. Em 1921 foi criado o Manicômio Judiciário do Distrito Federal; seguiram-se o Manicômio de São Paulo em 1923, o de Barbacena em 1929 e, posteriormente, em outros Estados. Na sua direção, a psiquiatria deveria ser dominante, mas na prática acabou subordinada pelo poder jurídico (JACOBINA, 2001, 110-111 pp.). A trajetória dos manicômios judiciários até os hospitais de custódia e tratamento é toda marcada por idas e vindas em um caminho que vai da punição à tentativa de tratamento.

Hoje, quando o delito é um sintoma da doença, guardando nexo causal com ela, o sujeito que o praticou é considerado inimputável pela lei. Diante desta inimputabilidade se dá o encaminhamento do doente ao manicômio judiciário. Sabe-se, no entanto, que os tratamentos manicomiais não têm sido bem sucedidos ao longo da história e que o louco infrator não tem benefícios previstos na Lei de Execução Penal (RELATÓRIO DE INSPEÇÃO DO HCT, 2003). Segundo Foucault (2001), a partir do exame psiquiátrico, o juiz pune não o crime ou delito, e sim suas condutas irregulares apontadas no exame como o lugar de formação do crime. A criminalidade é apreciada então do ponto de vista psicológico-moral, onde a doença já não é uma doença, é um defeito moral. O exame psiquiátrico deve realizar uma demarcação entre doença e responsabilidade, entre causalidade patológica e livrearbítrio do sujeito jurídico, entre terapêutica e punição, entre hospital e prisão. Quando o patológico entra em cena, a instituição médica deve (ou deveria ${ }^{2}$ ) tomar o lugar da instituição penal (FOUCAULT, 2001).

No país existem atualmente 33 Hospitais de Custódia e Tratamento - HCT's, com 3370 presos por medida de segurança (INFOPEN, 2010). Há ainda poucas reflexões sobre os HCT's e a maioria deles aborda questões do Direito ou questões institucionais. Entre os trabalhos científicos já realizados no HCT alvo do nosso estudo, encontramos as dissertações de Correia (2007): "Avanços e impasses na garantia dos direitos humanos das pessoas com transtornos mentais autoras de delito"; e de Peres (1997): "Doença e Delito", que trata da relação entre a psiquiatria e o poder judiciário; e tivemos acesso ao artigo de Lorenzo (2006): "O tratamento dos doentes mentais no Hospital de Custódia e Tratamento".

Em relação ao Brasil, encontramos trabalhos históricos, como a tese de Jacobina (2001): "A Prática Psiquiátrica na Bahia (1874-1947): Estudo Histórico do Asilo São João de Deus/ Hospital Juliano Moreira", e a tese de Kummer (2010): "A Psiquiatria Forense e o Manicômio Judiciário do Rio Grande do Sul: 1925-1941". Encontramos artigos como o de Sá (1985): "O Manicômio Judiciário, Saúde ou Justiça?" que aborda a adequação do Manicômio Judiciário estar subordinado à Secretaria de Justiça e não Secretaria de Saúde; o artigo de Moscatello (2001), "Recidiva criminal em 100 internos do Manicômio Judiciário de Franco da Rocha, que trata do comportamental criminal; o artigo de Almeida 
(2009): "Qualidade de vida de pacientes com esquizofrenia em Hospital de Custódia"; o artigo de Bravo (2007): "As Prisões da loucura, a loucura das prisões"; entre outros. Contudo, apenas o artigo de Cordioli (2006) "Hospital de Custódia: Os direitos preconizados pela Reforma Psiquiátrica e a realidade dos internos", aborda as vivências dos internos destas instituições. Não encontramos referências de trabalhos especificamente sobre as vivências de internos psicóticos nos HCT's do Brasil.

A instituição em que ingressamos para pesquisar ${ }^{3}$ tem capacidade oficial de 280 leitos. No entanto, recentemente foi determinada pela ANVISA a ocupação máxima de 140 leitos, sendo 20 femininos e 120 masculinos. A maioria dos internos-pacientes é do sexo masculino, e o crime de homicídio supera numericamente todos os demais.

Ao chegar ao HCT, pela primeira vez, o visitante se depara com um muro alto e branco, um grande portão de ferro azul. Há um prédio antigo, que corresponde ao local onde ficam os internos, um prédio ao lado que corresponde ao refeitório, cozinha, lavanderia, rouparia e terapia ocupacional, outro prédio, de construção mais recente, que constitui a parte administrativa da instituição, e um anexo ao lado do pátio externo, para a equipe de segurança. O pátio que cerca o prédio principal é grande, com bancos e árvores, um campo de futebol e uma área que corresponde ao estacionamento. No pavilhão administrativo temos as salas da diretoria geral e administrativa, a sala da chefia de segurança, a sala da Defensoria Pública, o arquivo, a farmácia, o setor de pessoal, uma sala de reunião, sanitários para funcionários e visitantes, copa, e as salas dos setores de psicologia, serviço social e terapia ocupacional.

No prédio do HCT destinado aos internos-pacientes, encontramos duas salas para a escola, a sala do setor de enfermagem, a sala do setor de higienização. Nas alas, além das enfermarias com os leitos, encontramos o posto de enfermagem, sala de atendimento, um sanitário coletivo. Na ala ' $E$ ' e na ala ' $A$ ' há um quarto individual, destinado aos internos-pacientes que tentam fuga, ou que se encontram agressivos. Faltam as regras sociais de privacidade, para os internos-pacientes, pois elas parecem não valer em instituições psiquiátricas como o HCT; os banheiros e sanitários das alas não têm porta, os dormitórios são coletivos, não há um lugar individualizado para guarda de pertences.

$\mathrm{Na}$ área do HCT propriamente dito, no prédio destinado à internação dos custodiados, a estrutura física é antiga e deteriorada, as escadas são estreitas, as paredes úmidas, é ambiente de pouca luminosidade e ventilação a que se soma o odor próprio dos antigos hospícios. As camas estão em precário estado de conservação, assim como os sanitários; a higiene, de um modo geral, é deficiente. Há uma grade trancada, que separa o posto de enfermagem do corredor das alas. A entrada de todas as alas é gradeada, assim como o são todas as janelas. $\mathrm{O}$ aspecto do prédio lembra mais um presídio do que um hospital.

\section{O método e técnicas de coleta: etapas e procedimentos}

Este trabalho de pesquisa é inspirado no interacionismo simbólico, que tem sido amplamente utilizado em pesquisas na área da saúde mental e ciências sociais (ANDRADE; TANAKA, 2000). A escola interacionista de pensamento parte do pressuposto de que o comportamento e a experiência humana são mediados pela interpretação. A atribuição de significados às relações entre indivíduos se dá através da interação dos mesmos. Assim, um fenômeno social precisa ser compreendido através da vivência dos participantes, dos significados atribuídos por eles, e decorrente das interações por eles constituídas (CHARON, 1989). Interação ocorre em qualquer ocasião em que um conjunto de indivíduos encontra-se na presença imediata de outros (GOFFMAN, 2007).

Importante deixar claro que o ponto de vista adotado neste trabalho de pesquisa é a visão de realidade apresentada pelas pessoas alvo deste estudo, os internos-pacientes, complementados com a dos internos-funcionários, observando como elas se enredam, ou se deixam enredar, na linha dos estudos de Becker (2008) sobre desviantes. Como parte da abordagem interacionista, têm sido aproveitados os recursos da metodologia conhecida como 'teoria fundamentada' (grounded theory), desenvolvida pelos sociólogos Barney Glaser e Anselm Strauss na década de 1960, que significa teoria derivada de dados, reunidos e analisados por meio de processo de pesquisa (GLASER; STRAUSS, 1967).

Esta metodologia é amplamente usada em pesquisas na área da saúde que vão desde enfermagem até a psicologia (MOREIRA; DUPAS, 2006; PAULI; BOUSSO, 2003). Esta amplitude se dá justamente porque este tipo de metodologia possibilita uma flexibilidade grande na construção do conhecimento de questões que, muitas vezes, constituem uma interseção disciplinar. Na teoria fundamentada importa a descrição do objeto de estudo e da cognição e ações dos atores retratados, além de organizar e, algumas vezes, classificar os dados segundo suas propriedades, e finalmente, teorizar a 
Como técnicas de estudo, adotaram-se a observação participante e entrevistas semiabertas. 0 trabalho de campo foi dividido em duas etapas: a. etapa de exploração e adaptação ao campo de pesquisa que correspondeu a uma observação geral da instituição, suas rotinas, e a familiarização com o seu funcionamento e com os que ali vivem ou trabalham. Posteriormente foram iniciadas conversas informais com internos-pacientes e com internos-funcionários; b. pesquisa de campo: realização de entrevistas semiabertas com internos selecionados para a nossa amostra central de pesquisa. Registros de prontuários clínicos e criminais e uma narrativa escrita por um informante integram a pesquisa como recursos complementares. Está sendo utilizado um diário de campo para registrar o observado e os conteúdos das conversas e entrevistas. Esta multiplicidade de fontes e técnicas de obtenção de informações pode garantir mais e melhores referências para nossa compreensão, beneficiando a qualidade de nossos achados (FLICK, 2009).

De acordo com Minayo (2007), na observação participante o observador fica em relação direta com os seus interlocutores, no espaço social da pesquisa, participando da vida social deles, na medida do possível, com a finalidade de colher dados e compreender o contexto. O pesquisador faz parte do contexto que observa, modifica e também é, por ele, modificado.

O trabalho de campo foi iniciado com idas ao HCT em distintos dias e horários, adquirindo-se uma 'familiaridade' com os internos-pacientes e os internos-funcionários, e pelo acompanhamento da rotina institucional, realizando observação participante a partir de momentos considerados chave, como refeições, tomada de medicações, visitas de familiares, horário livre no pátio, e a hora da tranca ${ }^{4}$. Quando das conversas informais com alguns internos-pacientes, sempre é feita uma apresentação e explicação sucinta sobre a pesquisa. Percebe-se que, sempre que me encontro no pátio, numa ala, ou no refeitório, alguns internos-pacientes se aproximam, acercam-se em pequenos grupos e fazem pedidos e queixas, expressando suas necessidades e denunciando parte das privações que passam na instituição.

Os pedidos surgem, na maioria das vezes, como o ponto inicial de uma aproximação para uma conversa. Eles pedem dinheiro, 'pacaia' ${ }^{5}$; que se telefone para suas famílias, que se interceda a seu favor junto ao juiz, ao diretor, ao advogado ou ao Serviço Social; pedem objetos de uso pessoal, como Saturnino, que está sempre a pedir um tênis, ou ainda: "eu quero um emprego quando sair daqui, como é que a gente faz"? pediu Arquimedes.

Quanto às queixas, iniciam-se geralmente pela alimentação: "a comida é muito ruim, o frango é só osso, e às vezes vem cru; a comida é sempre a mesma coisa", disse-me Rochester; "a comida é péssima, pode provar para ver", queixou-se Saturnino; "tem gente aqui que não gosta nem de soja, nem de ovo, eu não como", falou Onorino. Seguem-se outras queixas: "minha Medida6, tá vencida, tô esperando fazer o laudo", disse-me Lorisvaldo; "tô sem resposta do juiz, se quer me julgar, me julga logo, quer me botar na rua, bota logo", referiu Ferdinando.

Passado alguns momentos depois do contato inicial, o procedimento adotado foi o de colocar algumas perguntas mais gerais em uma linguagem simples: o que você pensa sobre este lugar aqui, o HCT? É hospital ou é prisão? O que aqui (HCT) tem de bom e o que tem de ruim? Como se sente estando aqui? Qual o motivo que Ihe trouxe para cá ? Você se considera doente? Em caso positivo, qual é mesmo a sua doença? Sobre o que mais você quer falar? Vale ressaltar que muitos dos dados foram coletados na presença de terceiros, o que para os internos-pacientes não parece fazer muita diferença, já que a maioria deles não omite os seus crimes, nem o seu histórico de vida ou os seus sintomas psicopatológicos.

Alguns internos-pacientes com características psicóticas e que cometeram homicídios narram seus crimes com detalhes, na frente de todos, aparentemente sem ressalvas; uns dizem que é bom falar para desabafar, outros dizem que falar sobre o ato homicida Ihes gera angústia, mas mesmo assim, falam. Temos visto que para eles, de uma maneira geral, este momento de conversa livre representa um meio de expressar suas identidades, manifestar suas crenças e também colocar suas principais demandas e angústias. Contou-me Ferdinando: "eu vim pra cá porque matei meus pais", disse Ferdinando; "eu vim pra cá por causa de homicídio, latrocínio, sequestro, tráfico de drogas, porte de arma, só por causa disso aí", narrou-me Aurino.

Da mesma maneira como feito com os IPs, foram começadas as conversas com os agentes penitenciários e demais funcionários, os internos-funcionários. Quanto às perguntas, adaptou-se boa parte das feitas com os internos-pacientes e foram acrescentadas duas: como se sente trabalhando aqui? $\mathrm{O}$ que pensa sobre os internos-pacientes? 
A aproximação com os internos-funcionários começou a ocorrer após as primeiras observações e conversas com internos-pacientes. Sozinhos, em dupla ou em grupo, suas falas, conversas e discussões têm sido muito frutíferas. As conversas em dupla ou em grupo são ricas, com debates, discussões, controvérsias e lembranças complementares nas falas dos companheiros. Geralmente elas se dão em seu setor ou sala de trabalho, mas também podem ocorrer no pátio, quando este não está ocupado por internos-pacientes.

Essas discussões em grupo, embora tenham características muito particulares, trazem também proximidades das vantagens obtidas através da técnica dos chamados grupos-de-discussão (BOHNSACK; WELLER, 2006). Segundo Weller: "as opiniões de grupo (Gruppenmeinungen) não são formuladas, mas apenas atualizadas no momento da entrevista. Em outras palavras: as opiniões trazidas pelo grupo não podem ser vistas como tentativa de ordenação ou como resultado de uma influência mútua no momento da entrevista. Essas posições refletem, acima de tudo, as orientações coletivas ou as visões de mundo do grupo social ao qual o entrevistado pertence" (WELLER, 2006, $245, p)$.

Exemplificando o ponto acima, em fevereiro de 2011, num início de noite, tive um frutífero bate-papo com um grupo de agentes prisionais do HCT no pátio. Disse Ribas: "aqui os pacientes falam com a gente assim: fulano me bateu e tá abusando de mim. Aí o que fazer? Eles não podem saber que o paciente falou, senão tem retaliação. Aí a gente dá um jeito de tirar o abusado da ala, mas não pune o estuprador". Antonina entrou na conversa:

"Aqui para mim, interno tem o que a lei dá, tem interna que quer fazer aqui o que quer. Chamo pro café, não vem, tem que ter disciplina, ordem, norma, se é interna, tem que cumprir, elas xingam, batem na porta do Posto de enfermagem, querem água, suco, pensam que aqui é hotel. Não dou nada a interna, e também não quero nada de interna".

Argumentou Ribas: "paciente que não aceitou lei lá fora, vai aceitar aqui? Muitos chegam do interior, não sabem nem que estão vindo pra cá, acham que estão vindo fazer exame; quando chegam, é pra ficarem internados; eles piram".

\section{A dinâmica do campo e análise da pesquisa}

Optou-se por não usar o gravador em nenhuma etapa do trabalho de campo, por considerá-lo um instrumento que pudesse despertar inquietação ou até mesmo algo de persecutório nos internospacientes. Esta expectativa fez sentido quando, num determinado dia, no início de uma entrevista individual com um interno-paciente, eu peguei o celular para por no modo silencioso, e ele perguntou se a entrevista seria gravada. Foi esclarecido que gravar não, mas anotar sim. Ele então disse: "ah! bom, assim está bem". Até então não fora observada qualquer resistência por parte dos informantes, aos constantes registros feitos. São registrados os relatos das observações, conversas, discussões e entrevistas manualmente no decorrer da fala dos informantes. O hábito profissional de ouvir longas histórias de pacientes ${ }^{7}$, e de registrá-las em prontuário, favorece a escuta das narrativas dos informantes da instituição pesquisada; é anotar ao mesmo tempo e depois, no mesmo dia, contando com os recursos mnemônicos, organizar a escrita, preenchendo porventura as falhas nas anotações.

Quanto aos requisitos éticos, o presente estudo foi submetido ao Comitê de Ética da FFCH da UFBA, em função de tratar-se de uma investigação com seres humanos no campo da saúde, obtendo aprovação em 07 de junho de 2010. Os pacientes internados no HCT alvo deste estudo estão sob a tutela do Estado, sendo necessária a autorização do dirigente da referida Instituição. Com isto, foi enviada carta ao diretor, solicitando autorização para coleta de dados, juntamente com um Termo de Responsabilidade do Pesquisador.

Os participantes da pesquisa são convidados a ler e, no caso de anuência, a assinar o Termo de Consentimento Livre e Esclarecido (TCLE), onde são expostos os objetivos da pesquisa, em observância aos requisitos éticos da Resolução 196/96 (BRASIL, 1996).

Em função do quadro patológico da clientela, é preciso ter bastante cuidado quanto à aplicação do TCLE. Alguns internos-pacientes assinaram o termo com muita tranquilidade, outros ficaram bastante temerosos ou persecutórios; um dos primeiros entrevistados, sem titubear, assinou de pronto o TCLE, tão logo foi terminada a leitura do mesmo: "me dê, que eu assino", disse ele. Outro se recusou a assinar, com receio de ter algum prejuízo no seu processo legal, já que estava no HCT para fazer laudo na tentativa de converter sua pena em medida de segurança.

É preciso avaliar bem o momento do TCLE em cada situação específica. Com um interno-paciente, com um nível de confusão mental e de produção psicótica tão intensa, foi prudente aguardar a 
evolução do quadro e um momento de maior lucidez para a assinatura do TCLE. Em todas as situações, tem importado aguardar o tempo necessário para se estabelecer um vínculo de maior confiança entre informante e pesquisador, exceto com o primeiro interno-paciente da amostra, pois já havia um conhecimento mútuo prévio de outra unidade de internação psiquiátrica da Bahia. O segundo integrante da amostra, antes de assinar o termo, disse: "se seu trabalho for dessa forma, eu aceito colaborar e assinar. A senhora garante que não vai causar nenhum problema pra mim nem pro outro"? Após a resposta ratificando que não causaria problema algum, o paciente levantou-se, botou a mão na cabeça, depois fechou os olhos, juntou as mãos próximas ao peito, parecendo pensar um pouco e em seguida falou: "vou assinar agora, já decidi"!

O perfil dos internos-pacientes, em sua maioria de baixa escolaridade, tem apontado a necessidade de, após a leitura do termo, fazer-se uma explicação com palavras mais simples sobre o conteúdo do mesmo, e o obter o consentimento verbal de que eles o compreenderam antes de assinar. Nestas ocasiões sempre é frisado que não haverá qualquer vantagem de ordem material ou de qualquer outra, para aqueles que participarem da pesquisa. Apesar deste esclarecimento, algumas falas de internos-pacientes, da amostra central ou não, colocam suas expectativas em relação à pesquisa que está sendo realizada: "espero que a senhora termine logo essa pesquisa e possa ajudar a gente melhorando alguma coisa aqui, essa é a hora mais triste, a hora da tranca, agora só sai amanhã"; ou "essa pesquisa da senhora vai ajudar eu sair daqui?" , ou, ainda, "a senhora pode me ajudar pra eu me aposentar"? A percepção de carência de atenção por parte dos internos-pacientes logo se evidencia. A fala geral de sofrimento causado pela instituição também é patente e se expressa claramente: "aqui é tudo ruim", disse um deles. Mas a fala mais marcante neste sentido até então, foi a seguinte: "eu fiz uma vítima, mas sou uma vítima, aqui sofro demais".

Quando das conversas grupais com os IPs, eles contam suas histórias, às vezes brincam com a própria desgraça, suavizando o peso dos assuntos abordados. Um interno-paciente um dia falou: "a senhora vir conversar com a gente é bom, a gente distrai, e a senhora parece que não tem medo de doido". Muitos notaram a minha familiaridade com o campo, e as nossas conversas acabam sendo, de algum modo, terapêuticas. Algumas das falas expressam este particular: "você conversar a respeito do caso depois que passou é bom que a gente desabafa". Em outra ocasião ouvimos: "doutora, a senhora pode conversar comigo, preciso desabafar, já pedi pra o agente me levar na psicóloga, ele não leva". O fato de eles estarem sempre a me chamar de doutora, me leva a pensar que na maioria das vezes não o papel de psiquiatra ${ }^{8}$ para eles é mais preponderante do que o de pesquisadora .

Os internos-funcionários acessados para conversas têm se mostrado em geral disponíveis, receptivos, colaboradores. Uma técnica de enfermagem aproveitou e entrevistou-me sobre o tema depressão, para um trabalho da faculdade. Encontrou-se uma resistência inicial por parte de uma interna-funcionária de nível universitário, que logo foi sanada após saber da minha profissão. Num outro caso, a resistência se deu exatamente por conta disto. Assim como com os internos-pacientes, também tem sido possível perceber a função terapêutica das conversas com os internos-funcionários. Certa feita, um agente prisional, no final de uma entrevista com um grupo de agentes disse: "a senhora devia ficar no plantão, ficar por aqui conversando, foi muito bom, a gente troca idéia, desabafa".

Entre internos-funcionários de diferentes setores há uma tensão, como entre o corpo médico e o corpo que faz a segurança. Um agente penitenciário narrou a seguinte situação:

No sistema penitenciário, a coluna cervical é o agente. Aqui não, quem comanda é o corpo médico. Na hora de botar um paciente numa determinada ala, eles não olham o lado da segurança, olham o lado clínico. Na hora que dá um problema, chamam o agente. Agora, o único recurso que se tem para contenção, é a medicação, não pode isolar, só pode fazer contenção mecânica se o médico mandar. Já houve um caso de um paciente contido ser assassinado à noite; com a contenção, o médico tirou a possibilidade de o paciente se defender. Se fosse o agente a decidir, ou transferia de ala, ou colocava no isolamento; mas o médico não ouve o agente.

Nas dinâmicas de campo sempre tem sido buscado o exercício de uma escuta muito atenta. De acordo com Lemgruber (1999) o pesquisador deve estar treinado para saber ouvir mais do que perguntar. As respostas iniciais ajudam a formular quase que naturalmente as próximas perguntas. Como mecanismo de checagem adicional quando da elaboração de alguma interpretação sobre o campo, tem sido importante voltar aos entrevistados e perguntar se o entendimento faz sentido ou se é equivocado. Quando são apontados problemas, pede-se novamente que a matéria em questão seja explicada pelos internos. Apenas o consentimento dos entrevistados, por si só, não valida os achados, mas este retorno efetivamente contribui para compreensão de sentido naquilo que na 
A análise das informações coletadas tem sido uma etapa que ocorre paralela ao curso do trabalho de campo, e não apenas no seu final (STRAUSS; CORBIN, 2008). Partindo deste pressuposto, até então já foram produzidos, como frutos do trabalho de campo, dois artigos surgidos da aparente confusão gerada na cognição dos internos, da mistura de duas instituições totais numa só,gerando uma terceira, absolutamente ambivalente, às vezes ambígua e outras vezes paradoxal, no dizer de Goffman (1999) em "O Paradoxo da junção Hospício e Prisão", e "Paradoxo ou Ambivalência? hospício e prisão - o caso do Hospital de Custódia e Tratamento".

À medida que a etapa de campo foi avançada, escrever sobre o observado e as reflexões já feitas a respeito, vem facilitando a organização do pensar sobre as bases possíveis do trabalho e quais as questões a serem aprofundadas. O campo aponta as suas problemáticas mais importantes, e é a partir delas que a pesquisa vem se delineando. Acresce-se aos dois artigos anteriores, este presente, que traz aspectos particulares metodológicos detectados durante o trabalho de campo, advindos da profissão da pesquisadora, do perfil da clientela alvo e da cultura institucional.

Tomando por base as orientações de Minayo (2007) para a análise de dados em pesquisa qualitativa, estão sendo observados os pontos em comum e as singularidades decorrentes da vivência de cada um. Busca-se identificar onde aparece a diversidade de opiniões e de significações em experiências aparentemente semelhantes, além de relacioná-las com aspectos vinculados à história do indivíduo e aspectos da cultura, especialmente daquela ligada à representação coletiva da loucura e a cultura de segregação. A descrição narrativa das informações tem sido feita de maneira fidedigna. Os termos usados pelos entrevistados são citados sem correções de concordância verbal, ou qualquer outra correção gramatical por entender-se que o modo como falam já diz um pouco sobre eles mesmos.

Um desafio adicional neste trabalho é integrar o saber da saúde mental e da psiquiatria forense, ao da sociologia do crime e do sistema prisional. Para Minayo (2007), a metodologia inclui a teoria da abordagem (método), os instrumentos de operacionalização do conhecimento (técnicas), e a criatividade do pesquisador (sua experiência, sua sensibilidade, sua capacidade pessoal, seu background). Há um ponto de tensão, pois é preciso o descolamento da identidade de psiquiatra para conseguir o olhar socioantropológico e evitar que tendências e crenças prévias sobre o campo, venham a distorcer os dados.

\section{O background, a técnica e o campo de pesquisa}

Pesquisadores que adotam técnicas qualitativas não temem partir de suas percepções ao iniciar a análise de seus materiais. É através de suas experiências que o pesquisador muitas vezes filtra a realidade, decodifica-a e Ihe dá sentido, até torná-la compreensível. Isto não quer dizer, no entanto, que estas experiências devam prevalecer ao observado em campo. O campo sempre será soberano e deverá ter espaço para falar por si (STRAUSS; CORBIN, 2008). Seguindo a lição de Geertz (1989), busca-se, nesta pesquisa, interpretar o sentido que o sujeito dá à sua experiência, na intenção de fazer uma "leitura da leitura". Aproveitam-se toda experiência e os conhecimentos adquiridos pela autora na área de saúde mental e sua familiaridade com instituições totais.

Apesar de exercer a prática psiquiátrica há mais de 26 anos, com vasta experiência de trabalho nas instituições de internação psiquiátrica em Salvador, procurei por uma que até então não conhecia e adentrei o HCT alvo deste estudo. A primeira visita foi em 2009, com a intenção de elaborar um projeto de pesquisa visando o ingresso no mestrado em Ciências Sociais. Concordo com Julita Lemgruber (1999) quando diz que é impossível passar por uma prisão e sair sem marcas e feridas. Impactei-me desde o primeiro momento com velhas e conhecidas imagens, acrescidas de outras inusitadas. Constatou-se desde as primeiras visitas, que além de toda a degradação já conhecida e própria dos hospícios, ali havia algo mais, talvez trazido pela junção, em uma única instituição de duas mazelas sociais, o hospício e a prisão. Mesmo com a intenção de melhor conhecer um universo novo, foi uma surpresa lá encontrar tantas coisas familiares e características de um hospício (universo mais conhecido pela autora), acrescidas das características prisionais ali materializadas. Diz-nos Lemgruber (1999) que "as prisões serão sempre as mesmas, não importa em que tempo ou lugar".

Para entrar no HCT, lancei mão da carteira do CRM e do título de psiquiatra, que nos autorizam ao trânsito livre na instituição, em qualquer dia e horário ${ }^{9}$, além do fácil acesso aos prontuários clínicos e aos criminais. Nestes dois pontos em especial, é importante lembrar que, além da formação e do reconhecimento do título de "doutora", uso das relações estabelecidas com os funcionários e com o diretor da unidade. Estes cartões de visita se mostraram muito valiosos e eficazes durante toda a pesquisa. No entanto, tento-me separar, o tanto quanto possível, deste papel e assumir 
Sentimos a necessidade de fazer incursões conjuntas e debater, após as idas a campo, os nossos pontos de vista. Este debate não era apenas entre orientador e orientanda, mas o contraste de duas formações e percepções sensíveis sobre uma mesma realidade, procurando foco e sintonia fina. Há clareza de que é preciso sair do olhar psiquiátrico que diagnostica e prescreve, estranhá-lo e tentar ver aquela realidade a partir do olhar do interno, do que é chamado ou se auto-intitula "louco", "perigoso", "homicida". Algumas vezes isto não tem sido possível: o campo, com suas particularidades, naturalmente tem solicitado o uso da fachada que naturalmente assumo na interação com pacientes psiquiátricos e que é por eles aprovada, como nos diz Goffman (2011).

Na situação acima descrita, lembrando a experiência da antropóloga Fernanda Eugênio (2003) numa escola para crianças cegas, acabei por fazer uma observação mais participante do que se poderia desejar (EUGÊNIO, 2003). Dois momentos foram marcantes: conversando com pacientes numa enfermaria, um deles sabendo estar diante de uma psiquiatra, apertou a cabeça com as duas mãos e disse: "tô ouvindo vozes, não tô aguentando mais, é a voz da minha irmã, ela diz que vai me matar". Ao perceber a forte angústia do paciente, solicitei da técnica de enfermagem da ala, que chamasse o médico de plantão para medicá-lo, esforçando-me para não pegar o prontuário e prescrever de pronto uma medicação.

Noutra ocasião, uma ambulância do Estado deixou um paciente do interior para ser internado na instituição, porém sem ordem judicial. A mãe ficou aflita, sem saber o que fazer, após o médico de plantão ter-Ihe dito que não poderia ficar com o paciente. Nesta hora, apontei possíveis soluções ao colega, para um melhor desfecho daquela situação. Foi aí que me dei conta que naquele momento ocupava outro papel, advindo de uma experiência passada na administração em uma unidade pública psiquiátrica. Nestas situações, tem sido quase impossível deixar de acumular os papéis de pesquisadora, o de gestora de unidade psiquiátrica e o de médica psiquiatra, pois as demandas institucionais acabam por gerar conflitos e necessidades subjetivas de encontrar uma solução plausível à situação problema.

Entrando em outro ponto, Gilberto Velho (2003) salienta, muito apropriadamente, que o pesquisador brasileiro em seus trabalhos geralmente se vale de sua rede de relações previamente existente e anterior à investigação. Importa colocar aqui que houve uma relação anterior da pesquisadora com o diretor do HCT em questão, por já termos trabalhado juntos, por alguns anos, em um hospital psiquiátrico. Este fato trouxe uma maior facilidade no trânsito no campo da pesquisa. Apesar do temor de que as mazelas institucionais sejam expostas ao público a partir de estudos realizados na instituição - como aponta Lemgruber (1999) no seu estudo numa prisão feminina - não houve, por parte do diretor do HCT, qualquer restrição a eles; foi-me dado acesso livre ao HCT, informando-se a funcionários-chave que atendessem a todas as solicitações que eu viesse a Ihes fazer. Para Goffman (2007), em um lugar limitado por barreiras estabelecidas à percepção, onde se realiza regularmente uma forma particular de atividade, ou seja, um estabelecimento social, evita-se que o auditório veja os bastidores e impede-se que estranhos participem de uma representação que não lhes é endereçada. Pelas razões já citadas, estas ressalvas para mim foram diminuídas.

A formação e atuação profissional como médica psiquiatra tem se mostrado um aspecto incontornável desta pesquisa, mas, a despeito disso, não me considero propriamente 'nativa' ou insider do HCT. Almeida (2011) discute muito bem as dificuldades e facilidades de ser 'nativo', insider na realização de uma pesquisa em ambiente prisional. As facilidades se dariam quanto ao acesso de informações e sujeitos que jamais seriam possíveis apenas a um pesquisador; as dificuldades se concentrariam mais em conseguir lançar um olhar menos naturalizado, de investigador, num ambiente tão trivial aos olhos de uma funcionária do sistema (ALMEIDA, 2011).

Em linhas gerais, Merton (1972) define Insiders e Outsiders da seguinte forma: insiders são membros de grupos específicos e coletividades ou ocupantes de um status social específico; outsiders, por sua vez, são os não membros. Usando esta definição mais estrita, sou outsider ao HCT, pois não faço parte do seu grupo de internos, quer sejam pacientes ou funcionários. No entanto, sou em parte insider pois, na qualidade de integrante do subgrupo de psiquiatras, acabei inserida neste contexto com naturalidade. Não foi sem propósito o fato de sentir-me imediatamente familiar com a instituição ao adentrar nela, isso apesar de jamais ter estado no HCT antes. Desde o primeiro dia, tive um sentimento de pertença, próprio dos naturalizados em hospício, quando nele ingressam. É importante lembrar, ainda segundo Merton (1972), que o outsider nunca será socializado ou engajado nas experiências do grupo social a que não pertence.

Na tentativa de melhor compreender a sociabilidade dentro do HCT, recorremos à contribuição de Goffman (2011). O intercurso social, segundo o autor, envolve uma dialética constante entre rituais de apresentação e de evitação. Deferência, para Goffman, é um meio simbólico pelo qual é 
comunicada a apreciação que um indivíduo mostra a respeito de outro para este outro, seja através de rituais de evitação ou de apresentação. Parece-me que os internos-pacientes assim se conduzem comigo, ao estarem sempre a me chamar de doutora e a reconhecer, com este símbolo, a minha autoridade sobre eles, legitimando o meu lugar de pertencimento.

Internos-funcionários também legitimam o meu lugar e me permitem determinados acessos dentro do campo por conta disto. Numa determinada tarde em que estive na sala do serviço social em busca do prontuário de um dos IPs da amostra central da pesquisa, um IF do setor, que eu ainda não conhecia, me disse:

- A senhora chegou aqui, deu boa tarde, disse quem era, pediu um prontuário, se for outro lugar, a senhora diz logo que é psiquiatra, se não a senhora não vai pegar prontuário nenhum. Tem uma funcionária aí, que vai criar problema pra senhora pegar prontuário.

- É no arquivo? (Ele balança positivamente a cabeça). Nunca tive problemas em pegar prontuários no arquivo.

- Então ela conhece a senhora, ou foi recomendada.

- É, talvez.

Segundo Becker (2008) não há estudos suficientes sobre como os desviantes vivem suas experiências de desvios, o que fazem ou pensam sobre si mesmo, sobre a sociedade e suas atividades. Uma das razões para isto, aponta Becker, é que não é fácil estudar desviantes; o estudioso do desvio precisa convencer aqueles a quem estuda de que não haverá perigo para eles, de que não sofrerão em consequência do que revelarem. Aqueles que cometem atos desviantes se protegem de várias maneiras contra outsiders intrometidos. Para Goffman (2011), importa na interação entre indivíduos a preservação da intimidade do outro, evitando perguntas que podem significar invasão do eu. No entanto, para determinadas pessoas de determinado estatuto, mudam-se essas regras.

No HCT, o meu estatuto de psiquiatra me confere a autorização a fazer perguntas pessoais sem constrangimento para mim ou para o interno-paciente que entrevisto, sem significar violação das fronteiras da personalidade do outro. Em função da minha posição no campo, um tanto híbrida, ou seja, nem exatamente insider, nem exatamente outsider, diminuiu-se o tempo necessário para conquistar a confiança dos estudados e para me familiarizar com o campo, por já ter um conhecimento da cultura psiquiátrica asilar e, de certo modo, usar destas expressões no campo do HCT. Assim, pude "queimar etapas".

Um determinado interno-paciente, como já citado, não aceitou fazer parte da amostra central da pesquisa, por receio de prejudicar o seu processo legal de algum modo. Nas nossas duas primeiras conversas, disse-me que havia coisas que preferia não falar, que só falaria no dia do laudo. No entanto, na nossa terceira conversa, narrou-me em detalhes uma trama delirante, que justificava a sua forte angústia; então the perguntei se foi aquele assunto que não poderia me contar. Ele disse: "foi, não sei por que falei, só falei isso pra uma doutora na $\mathrm{COP}^{10}$, e pra uma doutora aqui no HCT, mas brevemente, não falei tudo como hoje não". Um dia, questionei no pátio um grupo de internospacientes, sobre se conversariam comigo sem tanta reserva, caso eu não fosse psiquiatra. Disse-me um deles:

"Não, a gente fala tudo com a senhora porque a senhora é médica, entende as coisas e ajuda a gente, naquele dia que eu tava mal, a senhora conversou comigo, me ajudou e nem precisou de remédio, a senhora foi como uma psicóloga".

Falou-me outro interno-paciente: "a gente fala porque a senhora ajuda e resolve as coisas". Essas narrativas expressam que o que os internos-pacientes falam tem uma relação direta de 'para quem falam', como nos coloca Goffman (2011). Neste ponto, sabe-se que o fato de ser a pesquisadora uma psiquiatra, levou indiretamente os atores a trazerem determinados temas, o que certamente não fariam se fosse outra a formação profissional do pesquisador.

Estamos confiando em Anselm Strauss e Juliet Corbin (2008), quando dizem que a experiência profissional é uma potencial fonte de sensibilidade: pode bloquear a percepção, mas também pode permitir ao pesquisador mover-se mais rapidamente para uma área, por já estar familiarizado com o campo.

Não é possível prever aonde vamos chegar, ao final deste empreendimento de pesquisa. No entanto, sabemos que o campo nos mostra os caminhos a seguir e segui-los ou não depende da nossa capacidade em priorizar as leituras do campo às nossas. Entendemos que as interpretações adequadas são germinadas nele, porém, de certo modo, só nascidas desta inter-relação frutífera do 
campo com o pesquisador. Sabemos que há perguntas por fazer, há aquelas que ficarão sem respostas, e há narrativas que nos farão silenciar.

Finalizamos com um trecho de uma narrativa de um IP, Arquimedes, que, por si só, traz aspectos da vitimização na sua trajetória de doente mental e, agora, também de criminoso - inimputável mas, de alguma forma, pela sociedade, punido:

- Eu tava em crise, acabei tirando a vida da minha própria mãe [...] depois do fato ocorrido, eu fui trabalhar. Aí os policiais chegaram lá, ficaram com medo e me deram três tiros, dizendo que eu enfrentei todos eles, mas não é verdade [...]. Eu não tava com minha consciência normal, eu não tomava remédio direito, achava que era normal [...] o que eu fiz não foi porque eu quis, meu plano era comprar uma casa pra minha mãe, aconteceu tudo ao contrário, eu fiz uma vítima, mas sou uma vítima, aqui eu sofro demais $[\ldots]$.

\section{Referências bibliográficas}

AGUIAR, M.C.M. O Paradoxo da Junção Hospício e Prisão, 2010. Disponível em: http://www.interativadesignba.com.br/III SPSC/arquivos/sessao8/221.pdf .

ALMEIDA, O.L. Sem lugar pra correr nem se esconder: um estudo de vitimização no sistema penal baiano. Tese de doutorado em Saúde Pública, Salvador, 2011.

ANDRADE S.M.O.; Tanaka O.U. A avaliação de resultados em saúde sob a perspectiva do interacionismo interpretativo. Rev. IMIP 2000; 14(1): 7-12.

BECKER, H. S. Outsiders: estudos de sociologia do desvio. Rio de Janeiro: Jorge Zahar Ed., 2008.

BOHNSACK, R.; WELLER, W. O método documentário e sua utilização na análise de grupos de discussão. Educação em Foco. Revista do Programa de Pós-Graduação em Educação da UFJF. Número Especial, 2006.

BRASIL. Conselho Nacional de Saúde. Resolução no 196, de 10 de outubro de 1996.

CARRARA, S. Crime e Loucura: aparecimento do manicômio judiciário na passagem do século. Rio de Janeiro, EdUERJ; São Paulo, EdUSP, 1998.

CHARON, J.M. Symbolic Interactionism: an introduction, an interpretation, an integration. 3. ed. Englewood Cliffs, Prentice-Hall, 1989.

EUGÊNIO, F. De como olhar onde não se vê: ser antropólogo e ser tia em uma escola especializada para crianças cegas. In: VELHO, Gilberto; KUSHNIR, Karina (orgs.). Pesquisas Urbanas: desafios do trabalho antropológico. Rio de Janeiro: Jorge Zahar Ed., 2003. p. 208-220.

FLICK, Uwe. Qualidade na pesquisa qualitativa. Porto Alegre. Artmed, 2009 (Coleção pesquisa qualitativa, coordenada por Uwe Flick).

FOUCAULT, M. Os Anormais: curso no Collège de France (1974-1975). S. Paulo: Martins Fontes, 2001.

GEERTZ, C. A I nterpretação das Culturas. Rio de Janeiro: LTC, 1989.

GLASER, B.; STRAUSS, A. The discovery of grounded theory. New York: Aldene de Gruyter, 1967. $271 \mathrm{p}$.

GOFFMAN, E. Manicômios, Prisões e Conventos. São Paulo: Editora Perspectiva, 1999.

GOFFMAN, E. A Representação do Eu na Vida Cotidiana. Petrópolis, RJ, Vozes, 2007.

GOFFMAN, E. Ritual de Interação: ensaios sobre o comportamento face a face. Petrópolis, RJ: Vozes, 2011.

JACOBINA, R. R. A Prática Psiquiátrica na Bahia (1874-1947): Estudo Histórico do Asilo São João de Deus/ Hospital Juliano Moreira. Tese de Doutorado em Saúde Pública, Rio de Janeiro, 2001.

LEMGRUBer, J.; Cemitério dos Vivos. Análise sociológica de uma prisão de mulheres. Rio de Janeiro: Ed. Forense, 1999. 
LOURenÇO, L. C. ; AGuiAR, M.C.M. Paradoxo ou Ambivalência? Hospício e Prisão - O caso do Hospital de Custódia e Tratamento - HCT/BA, 2011. Disponível em: www.sistemasmart.com.br/sbs2011/.../29_6_2011_15_58_42.pdf-

MERTON, R.K. Insiders and Outsiders: A Chapter in the Sociology of Knowledge. The American Journal of Sociology, Vol. 78, No. 1, Varieties of Political Expression in Sociology (Jul., 1972), pp. 947. (article consists of 39 pages).

MINAYO, M. C. S. (org.) Pesquisa Social: teoria, método e criatividade. 26 ed. - Petrópolis, RJ: Vozes, 2007.

MOREIRA, P.L.; DUPAS, G. Vivendo com o diabetes: a experiência contada pela criança.Rev. Latino-Am. Enfermagem, Ribeirão Preto, v. 14, n. 1, Feb. $2006 . \quad$ Disponível em : <http://www.scielo.br/scielo.php?script=sci_arttext\&pid=S0104-

11692006000100004\&lng=en\&nrm=iso>. Acesso em: 04 Apr. 2011. doi: 10.1590/S010411692006000100004.

PAULI, M. C.; BOUSSO, R. S. Crenças que permeiam a humanização da assistência em unidade de terapia intensiva pediátrica. Rev. Latino-Am. Enfermagem, Ribeirão Preto, v. 11, n. 3, jun. 2003. Available at: <http://www.scielo.br/scielo. php?script=sci_arttext\&pid=S010411692003000300003\&lng=pt\&nrm=iso>. Access in: 04 abr. 2011. doi: 10.1590/S010411692003000300003.

RELATÓRIO DE INSPEÇÃO HCT - Ministério da Justiça, Secretaria Nacional de Justiça, Departamento Penitenciário Nacional; fevereiro/março 2003.

STRAUSS, A.; CORBIN, J. Pesquisa qualitativa: Técnicas e procedimentos para o desenvolvimento de teoria fundamentada. 2. ed- Porto Alegre: Artmed, 2008.

VELHO, G. O desafio da proximidade. In: VELHO, Gilberto; KUSHNIR, Karina (orgs.). Pesquisas Urbanas: desafios do trabalho antropológico. Rio de Janeiro: Jorge Zahar Ed., 2003. p. $208-220$.

WELLER, W. Grupos de discussão na pesquisa com adolescentes e jovens: aportes teóricometodológicos e análise de uma experiência com o método. Educação e Pesquisa, São Paulo, v. 32, p. 241-260, maio - ago. 2006. Disponível em : http://www.scielo.br/pdf/ep/v32n2/ a03v32n2.pdf. Acesso em: 17. set. 2007.

\section{Notas}

1 Este trabalho foi elaborado a partir de uma pesquisa em andamento em um Hospital de Custódia e Tratamento localizado em nosso país e que tem por intuito fornecer informações para elaboração da dissertação de mestrado de Márcia Cristina Maciel de Aguiar no Programa de Pós-Graduação em Ciências Sociais da UFBA, sob a orientação do Professor Luiz Claudio Lourenço. Esta tarefa também se dá de forma integrada a outras pesquisas desenvolvidas pelo grupo de Pesquisa LASSOS - UFBA sobre o sistema prisional baiano.

2 Esta observação é de nossa autoria

3 Para não expor pacientes nem a equipe que trabalha nesta instituição usamos pseudônimos e evitamos trazer outros dados identificadores dos atores entrevistados.

4 Durante o dia nota-se muito movimento nas alas, no pátio, na administração. Dependendo do horário, encontram-se muitos internos-pacientes no pátio, todos com farda amarela. Por volta das 17 horas, após a entrada dos mesmos nas alas, o pátio é ocupado pelos pombos, cães vira-latas, internos-funcionários da higienização, que fazem a limpeza, e agentes prisionais que ficam sentados nos bancos ou cadeiras. A brisa é agradável, e melhor vai ficando à medida que escurece. Há um silêncio no ar e certa tranquilidade aparente. Sentar ali pode parecer, muitas vezes, que se está num banco de uma praça, esperando o tempo passar.

5 Fumo artesanal.

6 Medida de Segurança.

7 Márcia Cristina Maciel de Aguiar é médica psiquiatra, atua há mais de 26 anos em instituições psiquiátricas públicas e privadas, exercendo função clínica e/ou administrativa. Atualmente preside a Associação de Pesquisa e Assistência Integral ao Ser, assume no Centro de Saúde do Psiquismo Inácio Ferreira funções clínica e de diretora técnica, além de exercer atividade como professora auxiliar do departamento de Neurociências e Saúde Mental da Faculdade de Medicina da Bahia - UFBA.

8 Sobre este aspecto em particular vamos tratar mais a frente neste texto. 
9 Certa feita, no início do trabalho de campo, eu pude conversar com alguns internos-pacientes dentro da ala, sem a presença direta de um agente prisional e/ou de um técnico de enfermagem, o que não seria possível se não fosse pela titulação de médica psiquiatra.

10 Centro de Observação Penal. 